\title{
Correction to: Thermal hydraulic considerations of nuclear reactor systems: Past, present and future challenges
}

\author{
Guan Heng Yeoh ${ }^{1,2}(\varangle)$ \\ 1. School of Mechanical and Manufacturing Engineering, University of New South Wales, Sydney, NSW 2052, Australia \\ 2. Australian Nuclear Science and Technology Organisation (ANSTO), Locked Bag 2001, Kirrawee DC, NSW 2232, Australia
}

(c) The Author(s) 2020, Corrected Publication November 2020

Correction to:

Guan Heng Yeoh

Thermal hydraulic considerations of nuclear reactor systems: Past, present and future challenges

Experimental and Computational Multiphase Flow 2019, 1(1): 3-27

https://doi.org/10.1007/s42757-019-0002-5

The article "Thermal hydraulic considerations of nuclear reactor systems: Past, present and future challenges" written by Guan Heng Yeoh, was originally published electronically on the publisher's internet portal (currently SpringerLink) on 08 April 2019 without open access. After publication in Volume 1, Issue 1, page 3-27, the author(s) decided to opt for Open Choice and to make the article an open access publication. Therefore, the copyright of the article has been changed to (c) The Author(s) 2020 and the article is forthwith distributed under the terms of the Creative Commons Attribution 4.0 International License (http://creativecommons.org/licenses/by/4.0/), which permits use, duplication, adaptation, distribution and reproduction in any medium or format, as long as you give appropriate credit to the original author(s) and the source, provide a link to the Creative Commons license, and indicate if changes were made.

The original article has been corrected and can be found at https://doi.org/10.1007/s42757-019-0002-5.

$\overline{\square \text { g.yeoh@unsw.edu.au }}$

(10) TNIINGHUA 